\title{
UM NOME, UM DESTINO: UMA ONOMÁSTICA NA FICÇÃO DE NELSON RODRIGUES
}

A NAME, A DESTINY:

AN ONOMASTIC IN NELSON RODRIGUES' FICTIONAL WORKS

Adriano de Paula Rabelo

Professor de Literatura Brasileira na Universidade Federal de Minas Gerais.

Via Atlântica, Säo Paulo, n. 38, pp. 338-362, dez. 2020. 
Resumo: Os nomes dos personagens são uma das mais importantes chaves de interpretação de uma obra ficcional, a ponto de chegarem a determinar os rumos da ação. Muito especialmente, eles dizem muito sobre quem são tais personagens, por que fazem o que fazem, como representam aspectos da realidade de uma determinada sociedade. Nas peças, romances, contos e folhetins de Nelson Rodrigues, escritor que tinha plena consciência desse poder expressivo dos nomes, a ponto de refletir frequentemente sobre isso em de suas crônicas ensaísticas, os nomes dados a seus personagens constituem um dos elementos a que o leitor ou espectador de seus trabalhos deve prestar grande atenção. Este artigo resulta de um amplo levantamento dos nomes de seus personagens, classificando-os em categorias e analisando brevemente seus sentidos, suas peculiaridades, suas relações com as personalidades que nomeiam.

Palavras-chave: Nelson Rodrigues, nomes, personagens, criação literária. 
Abstract: Characters' names are one of the most important keys to interpreting a fictional work. They can even determine the course of the story's action. Especially, they express a lot about who these characters are, why they do what they do, how they represent aspects of a specific social reality. In the plays, novels, short stories and newspaper serial narratives by Nelson Rodrigues, a writer who was fully aware of the expressive power of names, to the point of frequently reflecting on this issue in his essayistic newspaper columns, his characters' names are one of the aspects the reader or viewer of the his works should pay close attention. This article results from an extensive survey of Rodrigues' characters names, classifying them into categories and analyzing their meanings, their peculiarities, and their relation with the personalities they name.

Keywords: Nelson Rodrigues, names, characters, literary writing. 
Os nomes que um escritor dá a seus personagens constituem um dos aspectos mais expressivos da criação literária. Tanto que muitas obras, completamente centradas na personalidade do protagonista, o nome desse personagem é o próprio título ou o foco de interesse do título: Édipo Rei, Medeia, Gargântua e Pantagruel, Hamlet, Príncipe da Dinamarca, O engenhoso fidalgo D. Quixote de La Mancha, Tartufo, Ana Karênina, Memórias póstumas de Brás Cubas, Macunaíma. $\mathrm{O}$ nome carrega em si muitas indicações sobre quem é o personagem, sua história, sua personalidade e suas relações com o mundo. Tanto que alguns nomes de grandes personagens literários acabaram por ser adjetivados: "complexo de Édipo", "pulsão edípica”, "banquete pantagruélico”, “dúvida hamletiana", "plano quixotesco", "fulano é um tartufo" [hipócrita], para ficar apenas em alguns que derivam de nomes dos personagens mencionados acima. Um nome pode evocar força física ou de caráter: Hércules, Ulisses, Antígona, Nora, Capitão Rodrigo. Ou fragilidade física ou de caráter: Euclião, Iago, Quincas Borba, Blanche Dubois. Pela simples sonoridade de seus nomes, Svidrigáilov e Smerdiakov, dois canalhas criados por Dostoiévski, já suscitam antipatia no leitor antes mesmo que eles façam alguma coisa na ação dos romances Crime e castigo e Os irmãos Karamázov. Enfim, o nome de um personagem é tão essencial que toda uma psicologia e todo um destino parecem brotar dele e nele se moldar. 
Em $A$ ascensão do romance, Ian Watt (2010, p. 19-21) mostra como o surgimento desse gênero, em sua expressão moderna, no início do século XVIII, na Inglaterra, representou uma ampla ruptura com a tradição clássica na literatura. Um aspecto dessa renovação foi a mudança radical na forma como os escritores Daniel Defoe, Henry Fielding e Samuel Richardson passaram a nomear seus personagens:

Os preceitos da crítica clássica e renascentista concordavam com a prática literária, preferindo nomes ou de figuras históricas ou de tipos. De qualquer modo os nomes situavam as personagens no contexto de um amplo conjunto de expectativas formadas basicamente a partir da literatura passada, e não do contexto da vida contemporânea. (...) Mas os primeiros romancistas romperam com a tradição e batizaram suas personagens de modo a sugerir que fossem encaradas como indivíduos particulares no contexto social contemporâneo. Defoe usa nomes próprios de modo displicente e às vezes contraditórios; porém raramente escolhe nomes convencionais ou extravagantes. (...) Como assinalou um crítico contemporâneo, Fielding batizou suas personagens "não com grandiloquentes nomes fantásticos, mas com nomes que, embora às vezes tenham alguma relação com a personagem, possuem uma terminação mais moderna". (...) Não que, como vimos no caso de Richardson, não haja lugar no romance para nomes próprios que de algum modo são adequados à personagem em questão, porém essa adequação não deve interferir na função primordial do nome: mostrar que a personagem deve ser vista como uma pessoa particular, e não como um tipo. 
Ana Maria Machado (2003, p. 28), por sua vez, chega a interpretar o conjunto da obra de Guimarães Rosa à luz dos nomes de seus personagens. Ela ressalta a importância desse aspecto na construção de um trabalho ficcional, sendo inclusive determinante da concepção e da criação desse trabalho:

Quando um autor confere um Nome a um personagem, já tem uma ideia do papel que lhe destina. É claro que o nome pode vir a agir sobre o personagem e mesmo modificá-lo, mas, quando isso ocorre, tal fato só vem confirmar que a coerência interna do texto exige que o Nome signifique. É lícito supor que, em grande parte dos casos, o Nome do personagem é anterior à página escrita. Assim sendo, ele terá forçosamente que desempenhar um papel na produção dessa página, na gênese do texto.

\section{A obsessão onomástica de Nelson Rodrigues}

O jornalista Cláudio Mello e Souza uma vez chamou Nelson Rodrigues de "flor de obsessão", expressão que faria história e seria mencionada por Nelson muitas vezes em suas memórias e confissões. Entre as muitas obsessões pelas quais o escritor celebrizou-se, pode figurar certamente aquela que ele cultivava pelos nomes das pessoas e, também de seus personagens. Nos diversos gêneros em que produziu sua obra, em especial em suas crônicas de jornal, é muito recorrente que ele faça uma digressão para refletir 
sobre o poder do nome como definidor de um destino humano. Indo além da literatura, suas reflexões frequentemente analisavam nomes de personalidades históricas e culturais:

Não há nome intranscendente e repito: - qualquer nome insinua um vaticínio. Todo o destino de Napoleão Bonaparte está no seu cartão de visitas. Ao passo que um J. B. Martins da Fonseca não tem nenhum destino especial e vou mais longe: - não tem destino. Quando batizaram William Shakespeare, o padre poderia perguntar-lhe: - "Como vão tuas Obras Completas?" No simples "William Shakespeare" estava implícita a música verbal do seu teatro. (RODRIGUES, 1995a, p. 131)

Ou nomes de pessoas com as quais ele convivia:

Digo e repito, com indisfarçável deleite, esse nome admirável: Yan Michalski. Tenho um amigo que vive gemendo, em sua inconsolável frustração: - "O meu complexo é não me chamar Yan Michalski". Dirão vocês que um simples nome não quer dizer nada.

Quer dizer tudo. (...) Mas concordo que Yan Michalski é muito mais nome de violinista húngaro do que de crítico carioca. (RODRIGUES, 1996, p. 163)

Para ele, certos nomes possuem uma clara identificação com certas áreas de uma cidade, como, por exemplo, o subúrbio do Rio de Janeiro nos anos 1960:

E eis que, na terça-feira, pela manhã, dobro a esquina e quase esbarro com d. Odete. Com esse nome de Zona Norte, é minha vizinha em Ipanema. (...) na Zona 
Norte, para lá da praça Saenz Peña, há várias Odetes. (RODRIGUES, 1994, p. 35)

Também pode haver identificação com uma época:

Outro dia, o Belisário entrou, e já atrasado, na redação. Digo Belisário e vou dedicar-lhe outro parêntese. Reparem no som: - Belisário. Não parece nome de velho teatro digestivo, de antiga e espectral burleta? (...) Meu tio Chico casou-se com minha tia Yayá. Era o tempo machadiano em que as pessoas se chamavam Yayá. (RODRIGUES, 1995a, p. 156 e 291)

Há nomes associados a um destino anônimo e medíocre:

Vejamos o nome: - Lemos. Lemos, como Oliveira, é nome de vizinho. (...)

Clementino. Eis aí um nome que não diz nada, não insinua nenhum vaticínio, não emana nenhum mistério. Clementino, como Oliveira, é um nome de vizinho. (RODRIGUES, 1993a, p. 28 e 136)

Se determinados nomes são marcados por esse prosaísmo, outros possuem toda uma aura poética, uma verdadeira transcendência, a ponto de provocar uma atração irresistível:

Lili. Conheci o nome antes da pessoa. Um dia, eu estava na mesa, tomando café com macaxeira. E, então, alguém falou em Lili. Achei o nome lindo. Lili. Aquilo ficou gorjeando em mim. Faço, porém, a ressalva: - aos cinco, seis anos, não se faz nenhuma seleção auditiva. 
Para mim, qualquer nome era bonito. Morava na rua Dona Maria um "seu" Sepúlveda. Era capitão da Guarda Nacional e tinha bigodões. Sepúlveda, ou qualquer outro nome, vem com um halo de mistério, de graça ou de espanto. Que vontade de me chamar Sepúlveda. (...) E Lili foi, exatamente, a minha primeira paixão de menino. Antes de vê-la, eu a amei. Amei o puro nome, o puro som. Era a primeira Lili da minha infância. Cinco anos tinha eu. Ou seis. Vá lá, seis. Sentia que aquele nome insinuava um mistério ou, mais do que isso, um destino. Fui varado por um sentimento de pena e de medo. Como se Lili fosse alguém que já morreu e que só aparece, por um momento, na memória dos espelhos. (RODRIGUES, 1993a, p. 35-36)

O costume brasileiro de quebrar a formalidade e manifestar afeto ao chamar alguém pelo nome no diminutivo naturalmente não escapa ao escritor, que fará largo uso dessa prática em sua obra literária:

Não sei se é correto chamar Guilherme da Silveira Filho de Guilherme da Silveira Filho. Um nome, assim por extenso, como num cartão de visitas, nem sempre ilumina o nosso mistério pessoal. Estou falando de alguém que é muito mais Silveirinha do que Guilherme da Silveira Filho. Assim o chama a cidade; assim o chamam os conhecidos e os desconhecidos; assim o chamam os seus operários. E, mesmo quando há cerimônia, é o dr. Silveirinha. (RODRIGUES, 1995a, p. 144)

O Vianinha me evitava como seu eu transmitisse aos menos avisados, a lepra reacionária. Mas como posso malquerer a um inimigo que chamo pelo diminutivo. (RODRIGUES, 1996, p. 200) 
Por fim, ainda no campo dos costumes brasileiros acerca dos usos relacionados aos nomes, não escaparia a Nelson a forma como os empregamos em nossas expressões idiomáticas:

Qualquer um de nós já disse não sei quantas vezes: "Até aí morreu o Neves". Por que só o Neves e não o Batista, o Sepúlveda, o Tavares ou o Pacote? Até hoje ninguém sabe por que o povo escolheu esse nome, exatamente esse e não outro qualquer. Ainda hoje, ao sair de casa, ouvi alguém dizer a alguém a propósito não sei de quem: - "Ora, ora, até aí morreu o Neves". Aquilo ficou nos meus ouvidos. Eis a verdade: - "Neves" tornou-se, para mim, algo de impessoal, de encantado, de alucinatório. (RODRIGUES, 1993a, p. 253)

Como se vê, uma das vertentes da obsessão onomástica de Nelson Rodrigues era esse ímpeto de teorizar informalmente sobre aspectos diversos das funções e dos sentidos do nome que cada ser humano carrega em sua jornada pela vida. Mas será em sua produção ficcional (teatro, romance, conto, folhetim) que ele criará uma vasta galeria de nomes quase sempre muito significativos pela relação que possuem com a personalidade, a cultura, as idiossincrasias sociais e o comportamento daqueles que os portam. 
2. Os nomes dos personagens de Nelson Rodrigues

Antes de analisar a forma como o escritor nomeava seus personagens, vale destacar alguns momentos em que estes exprimem pensamentos acerca dos nomes. Muitas vezes isso reflete características da cultura brasileira, algo que Nelson Rodrigues valorizava bastante. Por exemplo, ao longo de toda a obra é muito comum, entre seus personagens, o costume de não se pronunciar o nome de alguém que morreu, como forma de respeito ao morto. Em vez disso, diz-se "o falecido", "o finado", "o defunto". No romance O casamento (1992a, p. 239), o protagonista Sabino, depois de sua ascensão social, passa a implicar e antipatizar com o nome "Arlete", por considerá-lo típico de alguém que pertence à baixa classe média. Na peça Os sete gatinhos (2003a, p. 844), "Seu” Noronha, ao tratar da hipocrisia da sociedade patriarcal, filosofa: "Nós usamos sobre a terra um nome que não é nosso, não é o verdadeiro, um nome falso!". E a certa altura do folhetim Asfalto selvagem (1995b, p. 301), ao conhecer uma possível namorada, Leleco - nome sempre associado a alguém fraco e malsucedido - faz-lhe desastradamente o seguinte galanteio: "Sabe que eu gosto do seu nome? Janet é um bonito nome. Eu acho bonito Janet. Nome bonito Janet. Nome bonito!".

Um levantamento feito nas 17 peças teatrais de Nelson Rodrigues, bem como em seu romance $O \mathrm{ca}$ - 
samento, em seus contos publicados nos volumes intitulados $A$ vida como ela é..., $A$ coroa de orquídeas e Pouco amor não é amor e, por fim, em seus folhetins intitulados Escravas do amor, Minha vida, Núpcias de fogo, $O$ homem proibido, A mentira, A mulher que amou demais e Asfalto selvagem contabilizou cerca de 550 nomes diferentes. Alguns deles se repetem muitas vezes em diversas obras. Outros sofrem variações de uma obra para outra, como "Helena”, "Lena”, "Leninha” ou "Ana”, “D. Ana”, “Aninha”. Retratando um costume brasileiro nas situações mais informais e no âmbito da cultura popular, o escritor muitas vezes faz com que seus personagens sejam chamados por apelidos, os quais abundam em sua obra. Da mesma forma, os nomes no diminutivo também se fazem muito presentes. Ele ainda aproveita nomes estrangeiros, nomes bíblicos, nomes abreviados, nomes de pessoas famosas, nomes de pessoas da vida real postos em sua ficção, sobrenomes e toda uma variedade de nomes comuns no Brasil. De um modo geral, percebe-se uma preferência de Nelson Rodrigues por nomes que provocam alguma ou muita estranheza, seja por serem bastante raros na sociedade brasileira, seja por serem francamente ridículos e indicarem aspectos grotescos da personalidade ou da aparência física de seus personagens.

Mas passemos à questão da forma como o escritor nomeava seus personagens e o efeito que ele tira disso. 0 levantamento realizado a partir da leitura de 
sua obra ficcional acima mencionada permite organizar os nomes de seus personagens em categorias. É o que se faz a seguir, analisando-se cada uma delas. Devido aos limites deste texto, no entanto, em cada categoria será apresentada apenas uma amostragem desses nomes.

\section{Uma galeria de nomes}

\subsection{Obsessões:}

Desde que se começa a ler o conjunto da obra de Nelson Rodrigues, logo chama a atenção uma verdadeira fixação que ele tinha por certos nomes. Estes se repetem em muitas de suas obras, seja nas mais "sérias", como sua obra teatral, seja nas mais desprestigiadas, como seus folhetins. Há uma ampla coleção de personagens chamados Glorinha, Silene, Leleco, Arlete, Guida, Paulo, Edgar, Lúcia, Carvalhinho, Sônia, Guilherme ou Dorinha, cujas personalidades, posição social e destinos se assemelham. Na obra do escritor, tais nomes evocam vidas comuns ou medíocres, bem como o universo suburbano ou de classe média baixa extensivamente retratado por ele. Apelidos e diminutivos remetem à informalidade e à afetividade consideradas marcantes nas relações interpessoais no Brasil, bem como enfatizam a pequenez do mundo ou do destino dessas personagens. 


\section{2. Nomes comuns:}

Nomes muito comuns no Brasil compõem uma extensa lista na onomástica dos personagens de Nelson Rodrigues. Todas as suas obras estão povoadas por figuras chamadas Clara, Marina, Flávia, Regina, Vicente, Raul, Gilberto, Teresa, Pedro, Carlos, Sérgio, Marisa, Geraldo, Oswaldo, Virgínia, Maurício... Apresentados dessa maneira, sem serem precedidos por um título de doutor ou seguidos por um sobrenome pomposo, tais nomes reforçam mediocridade da vida, da personalidade ou do destino daqueles que os carregam. São típicos "nomes de vizinho", como Nelson classificava certas denominações pessoais marcadas pelo prosaico e a intranscendência.

\subsection{Nomes de figuras históricas ou celebridades:}

Em suas crônicas ensaísticas e confessionais, Nelson Rodrigues costumava citar acontecimentos representativos envolvendo personalidades da história ou do mundo das artes, bem como frases marcantes que eles disseram, para dar sustentação a seus argumentos. Possuindo uma cultura geral ampla e variada, ele selecionava alguns desses acontecimentos e ditos, repetindo-os muitas vezes em seus textos, como era do feitio de suas obsessões. Em sua ficção, percebe-se uma presença considerável de personagens com nomes de personalidades históricas e celebridades. 
Como vários desses nomes são colhidos na Grécia antiga, em Cartago, na Pérsia ou nas artes estrangeiras, eles geram estranhamento por si só, além de muitas vezes provocarem um efeito cômico de contraste entre a grandeza do personagem do passado e a pequenez daqueles que os portam nas histórias do escritor brasileiro. Há também nomes de atrizes da era do cinema mudo, políticos brasileiros do passado, figuras da Idade Média e do Renascimento. Entre esses nomes, podem ser citados os seguintes: Epaminondas, Aristóteles Passarinho, Alcebíades, Laerte, Aristides, Asdrúbal, Dario, Elesbão, Ariosto, Pola Negri, Dorothy Dalton, Seu Floriano, Getúlio.

\section{4. Nomes bíblicos:}

Retratando a decadência da sociedade patriarcal, que sustentava todo o seu sistema de moralidade nos valores judaico-cristãos, Nelson Rodrigues expõe um mundo em que a Bíblia é uma constante referência de valores. No entanto, percebe-se uma notável maioria de nomes provenientes do Antigo Testamento: Jonas, Misael, Ismael, Elias, Daniel, Rafael, Miguel, Rute, Judite, Jeremias, Dalila, Jeová. Novamente essas figuras grandiosas, em geral profetas, anjos, reis, mulheres que praticam atos decisivos e até o nome do próprio deus de Israel contrastam com a pequenez, o grotesco ou mesmo a sordidez daqueles que portam seus nomes na ficção de Nelson Rodrigues, gerando um 
efeito cômico. Os nomes provenientes do Novo Testamento em geral diluem-se nos nomes muito comuns no Brasil, também adquirindo a condição de "nomes de vizinho", por sua popularidade num país de ampla maioria cristã, como o Brasil: João, Pedro, Ana, Simão, Tiago, Maria José, Nazaré, Belchior, Baltazar.

\subsection{Personalidades e nomes da vida real postos na ficção:}

Ao escrever suas histórias ficcionais, Nelson Rodrigues tinha o curioso e muito peculiar costume de transportar para suas histórias alguns de seus amigos jornalistas e escritores, postos um tanto subitamente no mundo ficcional, quase sempre gerando um efeito cômico. Lá se encontram Otto Lara Resende, Salim Simão, José Ramos Tinhorão, Paulo Mendes Campos, Hélio Pellegrino, Wilson Figueiredo, Amado Ribeiro. A exceção deste último, os outros são apresentados em chave bastante positiva, como se fossem homenageados. Em outras ocasiões, geralmente para espicaçar desafetos da hora, ele dava nomes de outros escritores e até de um jornal com o qual se desaveio a personagens extremamente negativas, como os perversos Drummonds da peça Senhora dos Afogados, o sórdido Sabino do romance $O$ casamento, o desvairado Olegário da peça $A$ mulher sem pecado e o estapafúrdio Dr. JB da peça Viúva, porém honesta. 


\subsection{Nomes estrangeiros:}

Personagens estrangeiros ou alguns que assumem nomes estrangeiros se fazem presentes em diversos momentos na ficção de Nelson Rodrigues. As cafetinas, em especial, costumam ser senhoras europeias de longa experiência no métier da prostituição ou brasileiras de nome europeizado, como Madame Clessi e Madame Luba. Isso supostamente conferiria alguma sofisticação à casa de meretrício que administram. Sendo a população brasileira formada em grande parte por imigrantes, isso se reflete na população das obras ficcionais de Nelson Rodrigues com sobrenomes diferentes daqueles de origem portuguesa: Dr. Werneck, Bergamini, Barone, Valverde. Há os personagens propriamente estrangeiros: Seu Saul, Miss Thorndyke, Prof. Petrescu. E há, por fim, um apelido de origem estrangeira: Bob.

\subsection{Sobrenomes:}

Diversos personagens são chamados pelo sobrenome da ficção de Nelson Rodrigues. Quando o sobrenome é precedido por um "dr.", como costuma ocorrer no Brasil, muitas vezes esse título não se refere a um médico ou a alguém que possui esse título universitário em qualquer área do conhecimento, mas é simplesmente um indicador do prestígio social e econômico daquele que o porta, quase sempre um 
homem branco, de meia idade, morador de algum bairro prestigioso do Rio de Janeiro, como Dr. Werneck, Dr. Portela, Dr. Guedes, Dr. Linhares, Dr. Barcelos, Dr. Maciel, Dr. Rocha Brito, Dr. Paschoal. Muitos personagens chamados pelo sobrenome, pelo prosaísmo e o lugar-comum de que seus nomes de família estão impregnados, também possuem o "nome de vizinho" e o correspondente destino medíocre ao qual o escritor costumava se referir em suas crônicas: Noronha, Cunha, Peixoto, Pimentel, Sampaio, Bezerra, Oliveira, Moreira, Queiroz, Meireles, Barbosa, Lemos, Menezes, Braga, Gouveia, Lima e tantos outros que fazem parte deste grupo. Por fim, há alguns personagens conhecidos por seus sobrenomes relativamente raros no Brasil, o que remete ao gosto que o escritor tinha pelo estranho, o inusual: Nepomuceno, Esmaragado, Piragibe, Segadas, Sarmento, Palha, Ribas. Em geral, este grupo compõe-se por personagens mais individualizados ou excêntricos.

Ainda uma palavra sobre formas de tratamento que precedem nomes ou sobrenomes na obra ficcional de Nelson Rodrigues: quando são precedidos por "madame" é certo que se refere a uma cafetina, dona ou administradora de bordel; e, quando precedidos por "tio" ou "tia”, há sempre uma conotação de velhice, sexualidade reprimida, perversão e conservadorismo no campo da moralidade patriarcal burguesa. 


\subsection{Nomes relativamente raros:}

Se Nelson Rodrigues joga com sobrenomes de relativa raridade no Brasil, também o faz com o primeiro nome. Aliás, ele faz isto o tempo todo ao nomear seus personagens. Entre todas as categorias de nomes apurados no levantamento feito em suas obras, esta é a mais extensa de todas, mais extensa inclusive que a dos nomes comuns. Nela foram apurados 152 nomes como Doroteia, Inézia, Oromar, Dr. Jubileu, Timbaúba, Aprígio, Arandir, Odésio, Alírio, Miécimo, Setembrino, Amarílio, Edgardina, Balduíno, Antoniel, Jupira, Filadelfo, Odaleia, Nemésio, Eurilo, Edila, Hula, Osmany, Clemilda, Zulema. Embora tais nomes realmente circulem pela sociedade brasileira, eles são bastante raros. Por si sós, já preparam o clima para a ruptura radical da normalidade cotidiana que sempre acontece na ficção de Nelson. Além disso, estão em sintonia com a estranheza que vem à tona com a irrupção da interioridade dos personagens do autor, movendo a ação de suas histórias.

\subsection{Nomes esdrúxulos ou grotescos:}

Se os nomes classificados na categoria anterior já provocam estranhamento, há um grupo de nomes que rompe as raias do bizarro. Uma figura frequentemente satirizada por Nelson Rodrigues, mesmo em suas tragédias, é o médico, que às vezes recebe 
uma variação no psicanalista. 0 ridículo dos médicos na obra do escritor já começa por seus nomes, quase todos carregados de um enorme ridículo: Dr. Bordalo, Dr. Borborema, Dr. Sanatório, Dr. Lambreta, Dr. Camarinha, Dr. Magarão, Dr. Areal. Outros personagens também recebem nomes com o fim evidente de ressaltar o grotesco de sua personalidade ou de suas ações: D. Assunta da Abadia, Diabo da Fonseca, Madame Cricri, Tia Assembleia, Tia Solteirona, Madame Crisálida, Baldomero, Aristóbulus, Engraçadinha, Almerinha, Dioclésio. Não por acaso, esses nomes são mais comuns nas farsas teatrais de Nelson, quando ele lança mão de uma sátira mais desbragada, rabelaisiana. Mas às vezes nomes assim aparecem também em seus folhetins, que também se marcam pelo exagero cômico.

\subsection{Alcunhas:}

Se a respeitabilidade social de figuras que representam o poder econômico faz com que se instaure toda uma formalidade no relacionamento com elas, a ponto de serem tratadas por "dr." sem o ser de fato, outras, desprovidas de elevado prestígio social, são chamadas por apelidos, fenômeno muito comum nos meios populares e familiares no Brasil, bem como em situações mais informais. Há, nas histórias de Nelson Rodrigues, toda uma profusão de alcunhas, tal como acontece nas casas, ruas, praças, botecos e campos 
de futebol brasileiros. Algumas derivam dos nomes dos personagens, realizando-se como formas afetivas originadas na infância: Dudu, Bebeto, Maneco, Guida, Quincas, Vadeco, Mag, Tia Zezé, Vavá, Tião, Lili, Malu. Outras, ainda que não derivem dos nomes oficiais, mantêm a carga mesma afetiva e familiaridade: Leleco, Nonô, Juca, Neném, Ziza, Tinoco, Nana. Outras tantas, pelo grotesco, a extravagância ou mesmo a vulgaridade que carregam, contêm claros ecos das chalaças de rua: Bibelot, Pardal, Gorda, Sabiá, Boca de Ouro, Caveirinha, Cadelão, Bunda Seca, Biguá, Cabeça de Ovo, Cabeleira, Bulau, Rolinha, Louro Mouco.

\subsection{Diminutivos:}

Muito presentes na linguagem brasileira, muito utilizados com forte carga afetiva quando aplicados aos nomes, embora algumas vezes com carga pejorativa, pode-se dizer que o diminutivo é também uma das obsessões de Nelson Rodrigues. Já o vimos utilizando essa derivação com mordacidade, em seus embates ideológicos com o dramaturgo Vianinha. E numa passagem da peça Anti-Nelson Rodrigues (2003a, p. 475), a personagem Tereza critica o marido numa discussão sobre o filho de ambos: "Você diz Oswaldo, nunca Oswaldinho. Não faz a seu filho a graça de um diminutivo."

Na maioria das vezes, na ficção do autor, de fato o nome no diminutivo simplesmente deriva do primei- 
ro nome do personagem, com conotação afetiva: Serginho, Glorinha, Selminha, Ritinha, Rosinha, Paulinho, Julinha, Laurinha, Alfredinho, Carlinhos, Alicinha, Teresinha, Lurdinha e tantos outros. Algumas vezes essa derivação acontece com nomes raramente encontrados no diminutivo: Arturzinho, Isaurinha, Eusebiozinho, Andrezinho, Antoninho, Alipinho. Outras vezes o nome no diminutivo deriva de alcunhas: Detinha, D. Senhorinha, Tuninho, Engraçadinha, D. Geninha, Ceguinho, Mineirinho, Doquinha, Leninha. Por fim, em alguns casos, mais raros, ele deriva de sobrenomes: Castrinho, Carvalhinho, Silveirinha.

\section{12. Aumentativo:}

Curiosamente o aumentativo associado ao primeiro nome para se referir a pessoas grandes, geralmente possuindo carga afetiva, bastante comum no Brasil, é raríssimo na obra de Nelson Rodrigues. No levantamento feito em sua obra ficcional, encontrou-se apenas um, ainda assim associado a uma alcunha: Cadelão.

\section{Considerações finais}

Tendo sido leitor voraz da subliteratura folhetinesca do fim do século XIX e início do século XX, tendo ele mesmo sido autor de diversos folhetins, além de aproveitar os recursos desse gênero em sua obra 
mais "séria", Nelson Rodrigues foi um escritor muito atento ao detalhe significativo. Muitas vezes esse detalhe era a chave para a resolução da trama e o desfecho dos enredos de suas histórias. Os nomes de seus personagens constituem seguramente detalhes muito significativos, sendo um dos aspectos aos quais o leitor ou espectador de seus trabalhos deve ficar atento. Como se viu, eles carregam conotações relativas ao tempo e ao lugar da ação, ao posicionamento social do personagem, seu universo cultural e a forma como se deve considerá-los.

Em suas obras, Nelson Rodrigues teve sempre grande preocupação em retratar o Brasil profundo em suas grandezas e misérias, principalmente em suas misérias. Do mesmo modo, preocupou-se em estilizar, em sua escrita, trejeitos típicos do linguajar brasileiro, muito especialmente os da fala coloquial. Uma análise dos nomes de seus personagens mostra que eles revelam - com seus apelidos, seus diminutivos, seus "nomes de vizinho", seu grotesco e seu lirismo - costumes e idiossincrasias de indivíduos e grupos bastante reconhecíveis na sociedade brasileira. Tais nomes são uma das chaves de leitura de uma ficção que nos diz muito sobre nossa realidade, sobre o que somos, sobre quem somos. 


\section{Referências}

AZEVEDO, Sebastião Laércio de. Dicionário de nomes de pessoas. Rio de Janeiro: Civilização Brasileira, 1993.

FLAG, Suzana. (Nelson Rodrigues). Meu destino é pecar. Rio de Janeiro: Ediouro, s/d.

FLAG, Suzana. (Nelson Rodrigues). Minha vida. Rio de Janeiro: O Cruzeiro, 1946.

FLAG, Suzana. (Nelson Rodrigues). Núpcias de fogo. São Paulo: Companhia das Letras, 1997.

FLAG, Suzana. (Nelson Rodrigues). Escravas do amor. São Paulo: Companhia das Letras, 2001.

MACHADO, Ana Maria. Recado do nome: Leitura de Guimarães Rosa à luz do nome de seus personagens. Rio de Janeiro: Nova Fronteira, 2003.

MYRNA. (Nelson Rodrigues). A mulher que amou demais. São Paulo: Companhia das Letras, 2003b.

PALLOTTINI, Renata. Dramaturgia: Construção do personagem. São Paulo: Ática, 1989.

RABELO, Adriano de Paula. Formas do trágico moderno nas obras teatrais de Eugene O'Neill e Nelson Rodrigues. Tese (Doutorado em Literatura Brasileira). São Paulo: Departamento de Letras Clássicas e Vernáculas da Faculdade de Filosofia, Letras e Ciências Humanas da Universidade de São Paulo, 2004. Teses - USP.

REUTER, Yves. Introdução à análise do romance. São Paulo: Martins Fontes, 1996.

RODRIGUES, Nelson. O casamento. São Paulo: Companhia das Letras, 1992a.

RODRIGUES, Nelson. A vida como ela é: 0 homem fiel e outros contos. São Paulo: Companhia das Letras, 1992b.

RODRIGUES, Nelson. $O$ óbvio ululante: Primeiras confissões. São Paulo: Companhia das Letras, 1993a.

RODRIGUES, Nelson. A coroa de orquídeas e outros contos de $A$ vida como ela é... São Paulo: Companhia das Letras, 1993b. 
RODRIGUES, Nelson. A menina sem estrela: Memórias. São Paulo: Companhia das Letras, 1994.

RODRIGUES, Nelson. $O$ reacionário: Memórias e confissões. São Paulo: Companhia das Letras, 1995a.

RODRIGUES, Nelson. Asfalto selvagem: Engraçadinha, seus amores e seus pecados. São Paulo: Companhia das Letras, 1995b.

RODRIGUES, Nelson. O remador de Ben-Hur: Confissões culturais. São Paulo: Companhia das Letras, 1996.

RODRIGUES, Nelson. Pouco amor não é amor: Contos. São Paulo: Companhia das Letras, 2002a.

RODRIGUES, Nelson. A mentira. São Paulo: Companhia das Letras, 2002b.

RODRIGUES, Nelson. Teatro Completo. Rio de Janeiro: Nova Aguilar, 2003a.

RODRIGUES, Nelson. O homem proibido. Rio de Janeiro: Agir, 2007.

WATT, Ian. A ascensão do romance. São Paulo: Companhia das Letras, 2010. 